\title{
BMJ Open Effects of maternal smoking on body size and proportions at birth: a register- based cohort study of 1.4 million births
}

\author{
Isabell Rumrich (D) , ${ }^{1,2}$ Kirsi Vähäkangas, ${ }^{3}$ Matti Viluksela, ${ }^{1,3}$ Mika Gissler, ${ }^{4,5}$ \\ Hanna de Ruyter, ${ }^{6}$ Otto Hänninen ${ }^{2}$
}

To cite: Rumrich I, Vähäkangas $\mathrm{K}$, Viluksela $\mathrm{M}$, et al. Effects of maternal smoking on body size and proportions at birth: a registerbased cohort study of 1.4 million births. BMJ Open 2020;10:e033465. doi:10.1136/ bmjopen-2019-033465

- Prepublication history and additional material for this paper are available online. To view these files, please visit the journal online (http://dx.doi. org/10.1136/bmjopen-2019033465).

Received 06 August 2019 Revised 05 December 2019 Accepted 30 January 2020

Check for updates

(C) Author(s) (or their employer(s)) 2020. Re-use permitted under CC BY-NC. No commercial re-use. See rights and permissions. Published by BMJ.

For numbered affiliations see end of article.

Correspondence to Dr Isabell Rumrich; isabell.rumrich@thl.fi

\section{ABSTRACT}

Objectives The aim of our work was to analyse the effect of maternal smoking on body size and body proportions of newborns when the mother had smoked only during the first trimester, in comparison with continued smoking after the first trimester. Furthermore, we have evaluated how growth restriction associated with maternal smoking contributes to changes in body proportions.

Design Register-based cohort study

Setting Maternal Exposure (MATEX) cohort identified from the Finnish Medical Birth Register.

Participants Singleton births without congenital anomalies and missing data (1.38 million) from 1 January 1991 to 31 December 2016.

Methods Logistic regression was used to quantify the effect of maternal smoking, stratified by the maternal smoking status.

Outcome measures Body proportions indicated by low brain-to-body ratio (defined as $<10$ th percentile); high ponderal index and high head-to-length ratio (defined as $>90$ th percentile); small body size for gestational age at birth (defined as weight, length or head circumference $<10$ th percentile) and preterm birth ( $<37$ weeks) and low birth weight $(2500 \mathrm{~g})$.

Results Continued smoking after the first trimester was associated with high ponderal index (OR 1.26, 95\% Cl 1.23 to 1.28$)$, low brain-to-body ratio $(1.11,1.07-1.15)$ and high head-to-length ratio $(1.22,1.19-1.26)$, corresponding with absolute risks of $22 \%, 10 \%$ and $19 \%$, respectively). The effects were slightly lower when smoking had been quit during the first trimester. Similar effects were seen for the body size variables and low birth weight. Preterm birth was not associated with smoking only during first trimester.

Conclusions Maternal smoking, independent of smoking duration during pregnancy, was associated with abnormal body proportions resulting from larger reduction of length and head circumference in comparison to weight. The effects of having quit smoking during the first trimester and having continued smoking after the first trimester were similar, suggesting the importance of early pregnancy as a sensitive exposure window.

\section{INTRODUCTION}

Smoking during pregnancy increases the risk for adverse pregnancy outcomes. Adverse pregnancy outcomes are not only associated

\section{Strengths and limitations of this study}

The register-based design of this study provided a big study size to detect small risks and minimises risks for recall bias.

- The register-based design of this study allowed for sensitivity analyses including stratification by socioeconomic status and birth year, as well as testing of additional adjustment models for sociodemographic factors and comorbidities.

- The data content of the Finnish Medical Birth Register has been validated for accuracy and completeness.

- Smoking status was self-reported during antenatal visits, leading to possible reporting bias.

- The register-based design restricted availability of information on confounders. Thus, lifestyle-related confounders, such as alcohol consumption and exposure to secondhand tobacco smoke, could not be adjusted for.

with complications in the neonatal period, but also much later, potentially in late adulthood. ${ }^{1}$ Tobacco smoke contains thousands of chemicals, which can cross the placenta and enter fetal circulation. Among them, nicotine has a multitude of adverse effects on the development of organs including brain. ${ }^{2}$ Other well-known toxic chemicals in tobacco smoke include carbon monoxide, which can interfere with oxygen supply of the unborn child, as well as genotoxic and carcinogenic polycyclic aromatic hydrocarbons and tobacco-specific nitrosamines, which are teratogenic in animal studies. ${ }^{3}$

The association between maternal smoking and low birth weight, commonly defined as weight below $2500 \mathrm{~g}$, is well established. In addition, data on the susceptibility of anthropometric indices, such as body length, head size and abdominal circumference to maternal smoking is emerging. ${ }^{4}$ Low birth weight as such does not hold information whether the reduction of weight is due to loss of lean or fat body mass. Similarly, reduction in any anthropometric index alone fails to 
identify abnormal body proportions. Symmetrical growth restriction in utero is a stronger risk factor for later life morbidity and mortality than asymmetrical growth restriction with decreased amount of fat tissue. ${ }^{5}$ Small for gestational age, used as a substitute for in utero growth restriction, is not an optimal proxy. ${ }^{6}$ This clearly demonstrates the importance of body proportions for future health of the newborn.

The effects of early smoking cessation on body size are not well understood. Smoking only during early pregnancy has been shown to be less harmful on body size than continued smoking during late pregnancy. Previous small studies have indicated that anthropometric indices in newborns exposed only during early pregnancy are similar to those in newborns of non-smoking mothers. ${ }^{7} \mathrm{On}$ the other hand, current bigger studies report increased risk for growth restriction even in fetuses exposed only during the first trimester. ${ }^{8}$ There are insufficient data about anthropometric indices, other than birth weight, in newborns exposed only during early pregnancy in comparison with newborns of non-smokers. ${ }^{9}$

The aim of our work was to analyse the effect of maternal smoking on body size and body proportions of newborns when the mother had smoked only during the first trimester, in comparison with newborns of mothers having continued smoking after the first trimester. Furthermore, we studied how growth restriction associated with maternal smoking contributes to abnormal body proportions. For this, we used the MATEX cohort identified from the Finnish Medical Birth Register. ${ }^{10}$ Additionally, we discuss the possibility of mechanistic interpretations of differences in body proportions in newborns of smoking mothers compared with non-exposed newborns.

\section{MATERIALS AND METHODS \\ Study design}

To study the effects of maternal smoking on body size and proportions at birth, we conducted a register-based cohort study using the Finnish MATEX cohort. The MATEX cohort was identified from the Finnish Medical Birth Register. It is described in more detail elsewhere. ${ }^{10}$ The Finnish Medical Birth register contains perinatal outcomes, pregnancy characteristics and sociodemographic information for all live births and stillbirths after the 22nd gestational week or with a birth weight of at least $500 \mathrm{~g}$. The Medical Birth Register receives information from standardised forms filled out by nurses and midwives during antenatal care visits and after the delivery of the baby.

This work focused on the effects of maternal smoking on singleton pregnancies delivered between the 1 January 1991 and the 31 December 2016. From initial 1.75 million mother-child pairs, 1.38 million were included in the analyses after exclusion of multiple births, newborns with congenital anomalies and newborns with missing information on maternal smoking status or the covariates (see online supplementary material, figure S1).
Within the MATEX birth cohort, information on head circumference and maternal weight and height, as well as maternal comorbidities was available only for the subpopulation born between 2004 and 2016. The subpopulation included 659157 mother-child pairs (see online supplementary material, figure S1). Thus, the analyses of endpoints related to head size (small head circumference, brain-to-body ratio and head-to-length ratio), as well as sensitivity analyses, were limited to the smaller subpopulation.

\section{Exposure}

Maternal smoking data are recorded in the Medical Birth Register during antenatal care visits as reported by the pregnant women. In the MATEX cohort, smoking status during pregnancy was assigned as three categories: (1) non-smoker; (2) quit smoking during the first trimester and (3) continued smoking after the first trimester. The trends in smoking during the study period have been described in detail elsewhere. ${ }^{11}$

\section{Outcomes}

Four groups of outcomes were included: (1) preterm birth (PTB); (2) low birth weight (LBW) (as a crude measure of small body size); (3) small body size for gestational age and (4) body proportions (table 1).

PTB was defined as a birth before gestational week 37, and term birth as birth during gestational week 37 or later.

LBW was categorised in accordance with the International Classification of Diseases 10th Revision (ICD-10) diagnostic criteria as weight below $2500 \mathrm{~g}$. As the reference category normal weight was defined as $2500-4500 \mathrm{~g}$, excluding high birth weight according to ICD-10 definition $(>4500 \mathrm{~g})$.

In this work, we use SGA as a general expression to describe the small size of the newborn. It was defined as measurement of body weight, body length or head circumference below a cut-off at 10th percentile, while the normal range defined as above the 10th percentile. Percentiles were defined based on sex-specific and parityspecific mean and SD for the corresponding gestational age (in weeks) at birth as reported in the Finnish standard reference population. ${ }^{12}$ It was included as an endpoint to take into account the impact of gestational age on body size.

Body proportionality was assessed by three anthropometric indices in relation with each other: ponderal index, brain: body ratio and head: length ratio. Percentiles of each ratio have been separately estimated for each gestational age (in weeks) at births in the study population. The 10-90th percentiles were categorised as normal and used as reference, while the tails of the distribution $(<10$ th percentile and $>90$ th percentile) were categorised as abnormal.

Ponderal index was calculated using birth weight and body length (Equation 1). It was categorised normal (10-90th percentile of the study population, used as the 


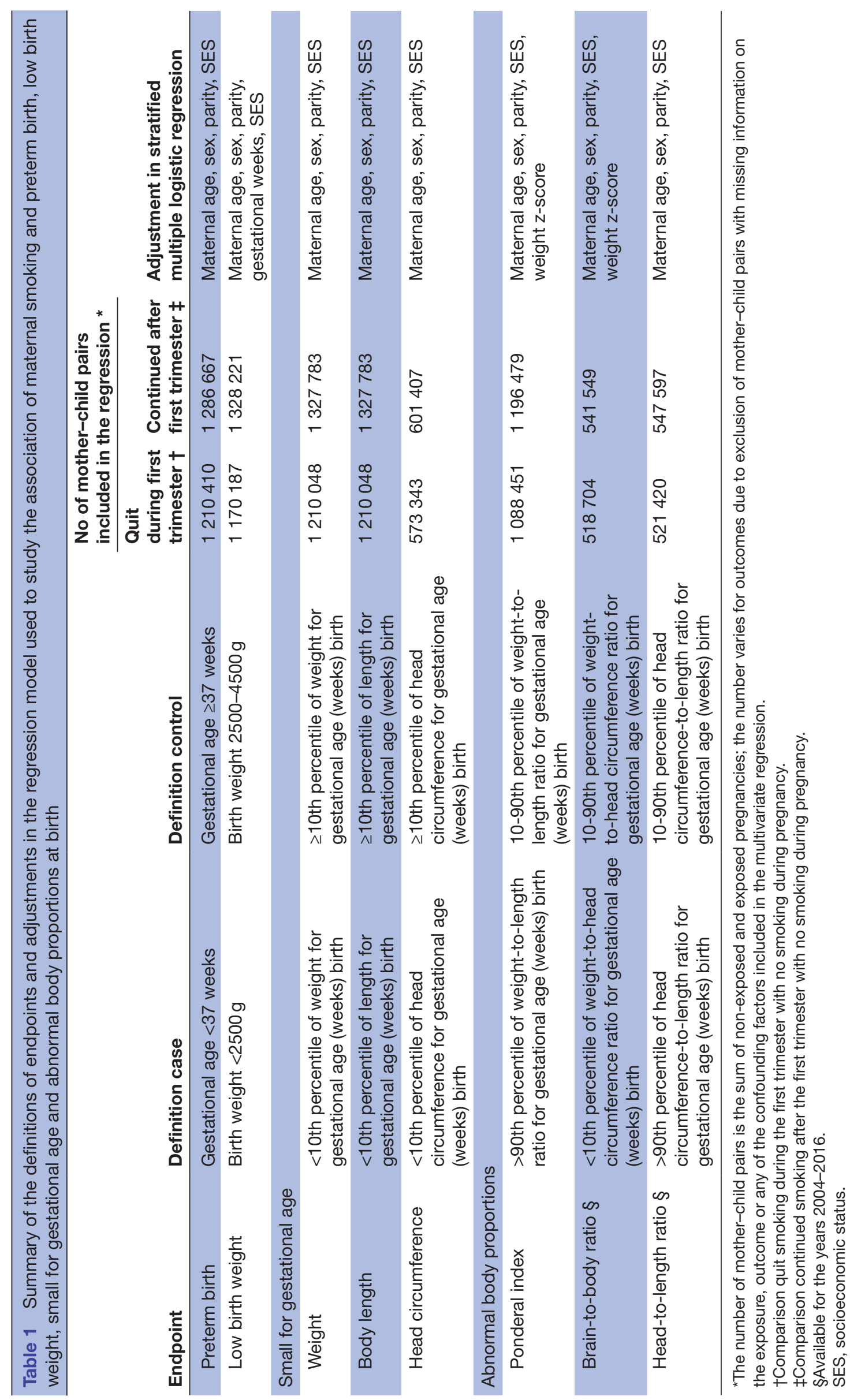


reference) and high (>90th percentile). Newborns below the 10th percentile were excluded.

$$
\text { Ponderal Index }=100 \times \frac{\text { birth weight }(\mathrm{g})}{\text { body length }(\mathrm{cm})^{3}}
$$

Brain-to-body ratio was calculated based on head circumference and birth weight (Equation 2). It was categorised as low ( $<10$ th percentile of the study population) and normal (10-90th percentile, reference). Newborns above the 90th percentile were excluded.

$$
\text { Brain }- \text { to }- \text { Body Ratio }=100 \times \frac{0.037 \times \text { head circumerence }(\mathrm{cm})^{2.57}}{\text { birth weight }(\mathrm{g})}(2)
$$

The nominator of the formula is the estimation of the brain weight according to the National Institute of Neurological and Communicative Disorders and Stroke's Collaborative Perinatal Project. ${ }^{13}$

Head-to-length ratio was calculated using head circumference and body length (Equation 3). It was categorised normal (10-90th percentile of the study population, reference) and high ( $>90$ th percentile). Newborns below the 10 th percentile were excluded.

$$
\text { Head }- \text { to }- \text { Length Ratio }=\frac{\text { head circumference }(\mathrm{cm})}{\text { body length }(\mathrm{cm})}
$$

\section{Covariates}

Maternal age and gestational age in weeks were used as continuous variables in the regression models. Parity was defined as nulliparous or multiparous. Sex was defined as male or female. Socioeconomic status (SES) was categorised as upper white collar (upper level employees with administrative, managerial, professional and related occupations), lower white collar (lower level employees with administrative and clerical occupations), blue collar (manual workers) and others (farmers, self-employed, students, pensioners), based on the Finnish national classification of occupations. ${ }^{14}$ An additional category (information missing) was added to this classification.

\section{Statistical analyses}

Multiple logistic regressions were performed to estimate ORs with $95 \%$ CIs. The regressions were stratified by exposure status with no smoking as reference, that is, smoking after the first trimester was compared with no smoking, and separately smoking only during the first trimester was compared with no smoking. The regression models were adjusted for potential confounders (table 1; online supplementary material, chapter 3.2 ). The potential confounding factors were selected based on a combination of available data and previously published factors that could affect both maternal smoking and the outcome measures. The data were analysed using $\mathrm{R}$ Statistical software V.3.4.3. The study power was estimated as the smallest detectable risk ratio. The calculations were done using R Statistical Software epiR package with assumed 95\% CI and a study power of $90 \%$ (see online supplementary material, table S1).

\section{Register data permit}

Due to the full register-based design of the study, noinformed consent was required from the study participants according to theFinnish Personal Data Act 1050/2018.

\section{Patient and pubic involvement}

No patients were involved in the design, recruitment or conduct of the study. The used register data are routinely collected in Finland.

\section{RESULTS}

Of all women with singleton births included in this study $(\mathrm{n}=1376778), 84.5 \%$ were non-smokers, $3.5 \%$ quit smoking during the first trimester and $12.0 \%$ continued smoking after the first trimester. Smoking pregnant women were younger and more likely to be nulliparous (table 2, supplementary material, table S2).

Any maternal smoking was associated with an increased risk for SGA and abnormal body proportions, while PTB was only associated with smoking continued after the first trimester (figure 1; online supplementary material, table S3).

Any maternal smoking increased the risk for LBW $(<2500 \mathrm{~g})$. Smoking continued after the first trimester in comparison to no smoking was associated with twice as high a risk for LBW (OR 2.22, 95\% CI 2.14 to 2.30). Smoking only during the first trimester was also associated with an increased risk for LBW compared with nonsmokers (OR 1.10, 95\% CI 1.02 to 1.19) although not as strong as with continued smoking (figure 1A).

Any smoking during pregnancy was associated with an increased risk for weight or body length at birth being below the 10th percentile. Mothers who quit smoking during the first trimester were at elevated but not statistically significant risk for giving birth to a child with a small head circumference. Among the newborns of the mothers who continued smoking after the first trimester the risk for small head circumference was clearly increased with an OR of 1.64 (95\% CI 1.60 to 1.68) (figure 1A).

The risk for abnormal body proportions of newborns was significantly increased by any maternal smoking. A stronger increase in risk was observed for high ponderal index and high head-to-length ratio than for low brain-tobody ratio. ORs were consistently higher if smoking was continued after the first trimester than when the mothers quit smoking during the first trimester. Nevertheless, smoking only during the first trimester was associated with statistically significantly increased risks for abnormal body proportions in newborns. Especially the risk for brain-to-body ratio was almost similar in those exposed only during the first trimester and those exposed also after the first trimester (figure 1B).

We stratified the analysis by SES to investigate the influence of lifestyle factors and health behaviours that correlate with SES. Stratification by SES did not result in statistically significant differences in the risk estimates between the SES groups (see online supplementary 
Table 2 Baseline characteristics by smoking status for singleton births in the MATEX cohort (1991-2016)

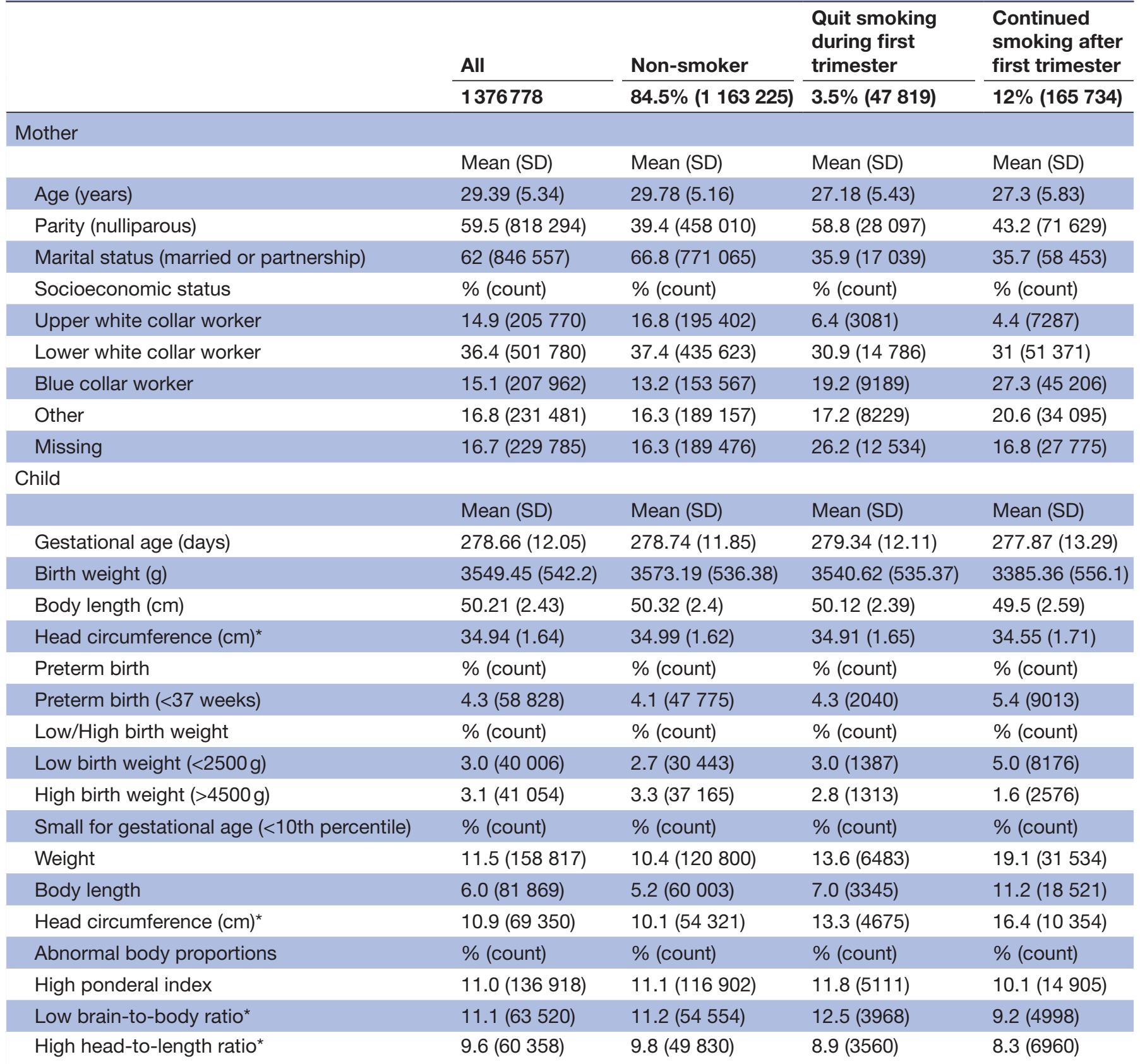

*Available since 1 January 2004.

material figure S2). We stratified the data by birth year to investigate potential influence of changes in the composition of tobacco (eg, use of additives and changes in tar and nicotine content) and decreased social acceptability of smoking during the study period on the risk estimates. Stratification by birth year did not indicate a clear temporal pattern in risk estimates for any of the analysed endpoints (see online supplementary material, figure S3). Sensitivity analysis was performed to test the sensitivity of risk estimates to choice of adjustment factors in the regression model. Alternative multivariate adjustment models, including comorbidities or additional socioeconomic factors, did not significantly alter the risk estimates for any of the reported endpoints (see online supplementary material figure $\mathrm{S} 4$ ).

\section{DISCUSSION}

In this work, we investigated the effect of maternal smoking during pregnancy, categorised as quit during the first trimester and continued after the first trimester on preterm birth, on body size and body proportions at birth. The most important finding of our study is that although the risk for low birth weight decreases by smoking cessation during the first trimester, brain size and body length in relation to body weight seem not to catch up. Among 


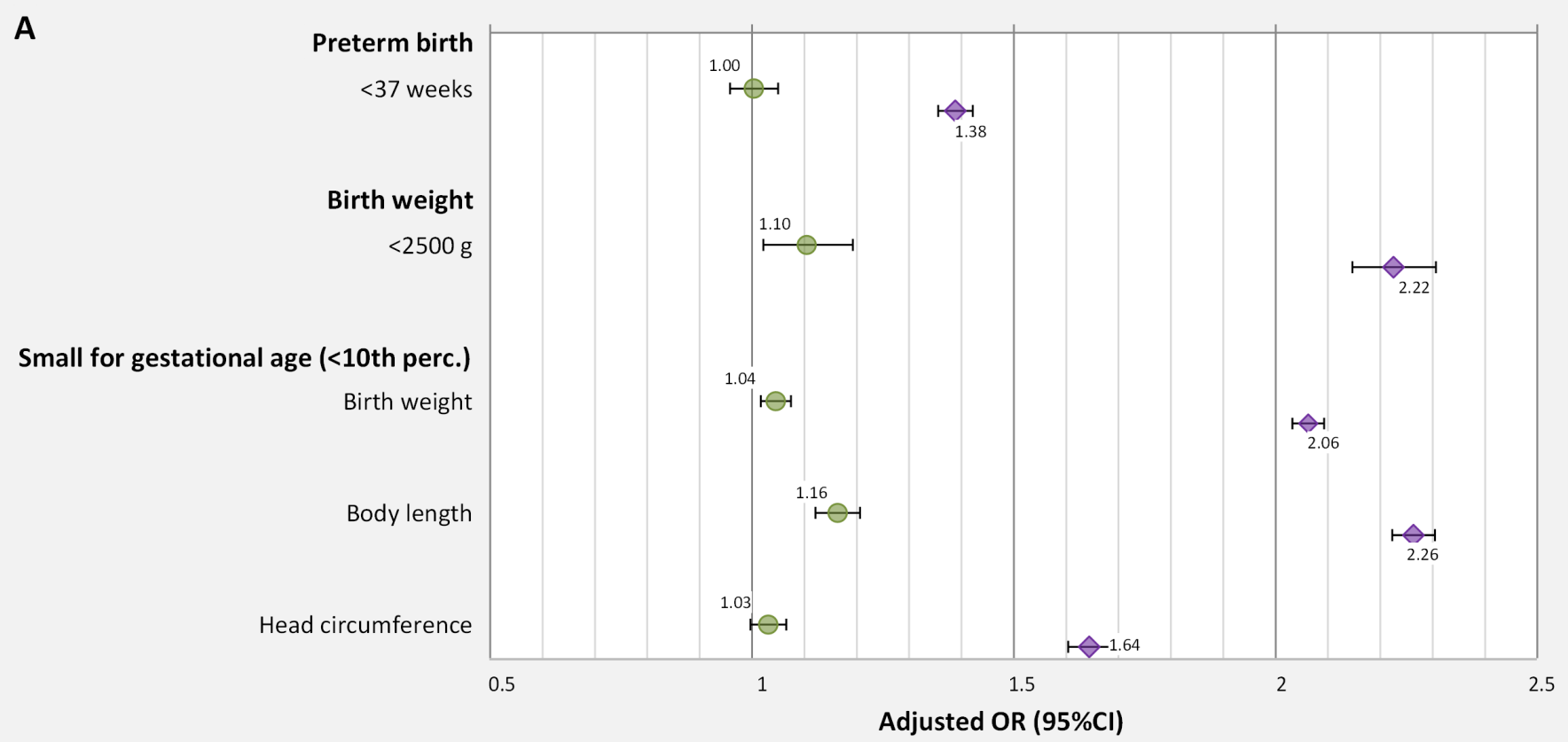

B

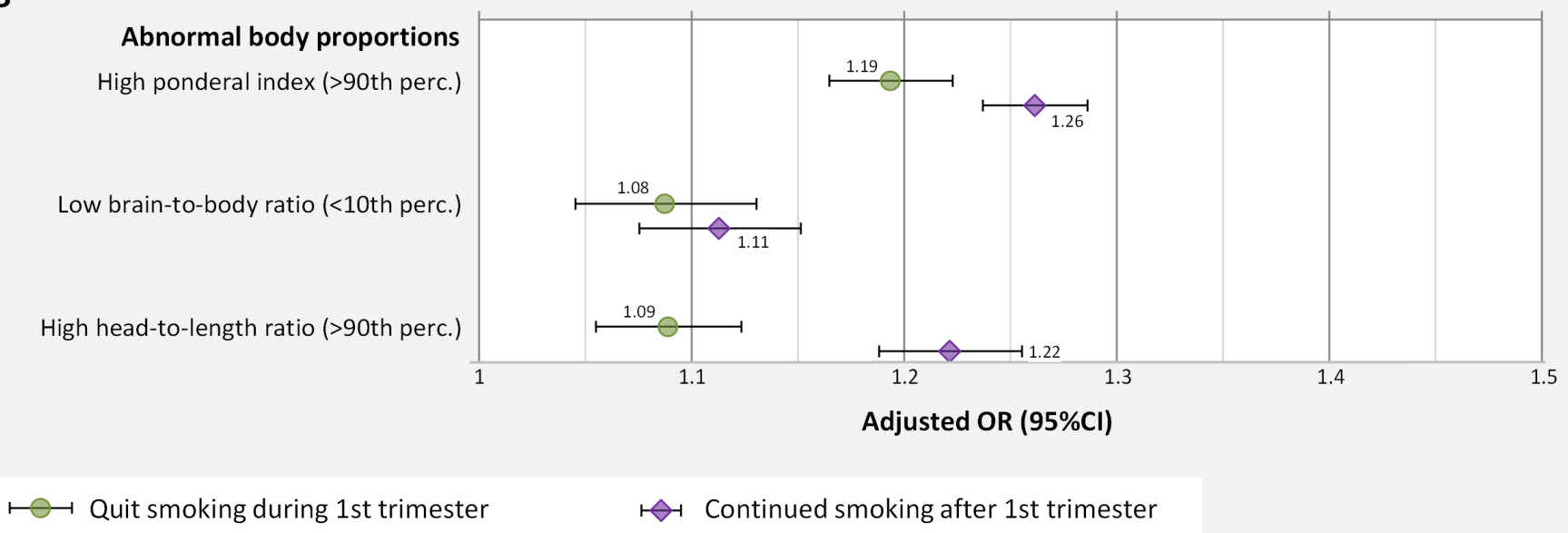

Figure 1 Adjusted ORs for association of maternal smoking with (A) traditional birth outcomes (preterm birth, low birth weight and small for gestational age); and with (B) abnormal body proportions; adjusted for maternal age, sex, parity, socioeconomic status and gestational week (for low birth weight) and weight z-score (in regressions with weight included in the dependent variable); marker+error bar: OR $(95 \% \mathrm{Cl})$.

the newborns exposed to maternal smoking only during the first trimester all three measurements of body size (birth weight, body length and head circumference) showed signs of growth restriction. In addition, body proportions were abnormal.

Our work indicates a difference in susceptibility for growth restriction between weight, body length and head circumference. The observed positive association of maternal smoking with ponderal index suggests a stronger reduction in length than in weight. Similarly, the association with low brain-to-body ratio suggests reduction rather in brain size than in weight. However, the association of maternal smoking with high head-to-length ratio suggests a stronger reduction in length than in head size. It is in line with previous research showing that smoking during pregnancy predominantly affects lean body mass and not fat tissue. ${ }^{4}$ While the associations with reduced body size and abnormal body proportion were stronger in newborns of mothers who continued smoking after the first trimester, there was a clear association also in newborns exposed only during the first trimester. This can be interpreted as an effect of maternal smoking on cell proliferation during organogenesis in early prenatal development. Insults during this period have been shown to persist throughout life. ${ }^{5}$ This stresses the importance of smoking cessation before pregnancy since even smoking only during early pregnancy has potentially devastating effects on long-term health of the unborn child.

The importance of body proportions at birth has been summarised by Zanelli and coworkers. ${ }^{15}$ Children born 
small and thin were shown to be more likely to develop coronary heart disease as obese adults than their peers who were born small but not thin. It is not possible to infer from our study whether the high ponderal index and higher risk for shorter body length is comparable to stunting due to malnutrition and infections. Mechanistic studies of the observed effects are needed to extrapolate the risks to later life.

Additionally, smaller head circumference has been shown to directly translate into a smaller brain. ${ }^{16}{ }^{17}$ Insults during early development of the brain, such as maternal smoking, have been shown to result in differences in DNA methylation, altered expression of genes regulating brain structure and function ${ }^{18}$ and reduction in neuronal content of the brain. ${ }^{19}$ Also, neurophysiological functions and overall brain functions are altered due to prenatal smoking. ${ }^{20}$ The smaller brain volume observed in newborns has been shown to persist into young adulthood. ${ }^{21}$

Overall, our results are in line with previously reported studies by other groups (see online supplementary material, table S4) ${ }^{22-25}$ Smoking quit during the first trimester had a weaker effect on reduction in weight or length measures, whereas smoking especially at the end of pregnancy reduced femur length, abdominal circumference and biparietal diameter. ${ }^{26} \mathrm{~A}$ clear dose response of smoking (number of cigarettes per day) on reduction of birth weight and increase in ponderal index has been demonstrated. ${ }^{1727}$ Previous studies examining the effect of smoking cessation during pregnancy have consistently reported a reduction in harm compared with continued smoking. ${ }^{4}$

There is increasing evidence from animal studies of nicotine as a causative agent for reproductive toxicity, including detrimental effects on brain. ${ }^{28}{ }^{29}$ In a large epidemiological study, among the few existing ones, aberrations in lung development due to nicotine replacement products used during pregnancy has already been suggested. ${ }^{30}$ Epidemiological studies on the effects of nicotine products, other than cigarettes, are still needed. We recommend the inclusion of information on the use of nicotine products in the Medical Birth Register. This would allow detecting pregnancies at risk more reliably and facilitating epidemiological research on nicotine exposure during pregnancy beyond maternal smoking.

This work is solely based on routinely collected register data, which dictates the data availability. We tested our results for sensitivity to different adjustment models. Our results were robust against inclusion of maternal comorbidities, maternal anthropometric indices, social background and reproductive history as confounders in the statistical model. Smoking and socioeconomic status have been shown to correlate well with other lifestyle related factors and they are reliable markers for the unaccounted factors. ${ }^{31}$ The smoking information was self-reported by the mother during antenatal care visits. Thus, reporting bias cannot be excluded. It was not possible to analyse the impact of timing of smoking cessation in more detail or possible dose-response relationships due to lack of data. In addition, we lack information on paternal and household smoking. Secondhand tobacco smoke exposure during pregnancy has been shown to increase the risk for low birth weight and growth restriction. ${ }^{32}$ We cannot exclude the possibility that some observed effects are partly attributable to secondhand tobacco smoke exposure, especially in those women who ceased smoking during their first trimester. Our definition of indicators for body proportions were constrained by available data in the register. Ideally, the outcomes in this work would be supplemented with clinical criteria collected during for example prenatal ultrasound scans, such as femur length, abdominal circumference and skinfold thickness. Further, the cut-off at the 10th percentile for the definition of small body size and abnormal body proportions was arbitrary due to a lack of clear data on a threshold for increased risk for complications later in life. Socioeconomic status was assigned here solely on maternal occupation and no information about the father's occupation was available. For a high proportion of mothers (18\%) the occupation was not available. Previous studies applied the same SES categorisation and showed that the missing information did not bias the proportions in the other SES categories. ${ }^{24}$

Study strengths include the register-based design with a large study size and practically complete population representativeness. Earlier analyses on the occupation codes available in the Medical Birth Register have shown that the socioeconomic confounding is reasonably well taken into account. Overall, occupation is well correlated with education and income in Finland, and it can be used as an indicator for socioeconomic health differences. ${ }^{33} 34$ An earlier study showed a reasonable match between serum cotinine and self-reported smoking status as applied in the Medical Birth Register. ${ }^{35}$

\section{CONCLUSIONS}

This study showed that maternal smoking is associated with a stronger reduction in body length and head circumference than in birth weight, leading to changed body proportions. The effects on body proportions of having quit smoking during the first trimester or having continued smoking after the first trimester were similar, stressing the importance of early pregnancy as a sensitive exposure window. Furthermore, it suggests a limited potential to repair fetal damage induced in early pregnancy. Lower brain-to-body ratio suggests that any smoking during the pregnancy may lead to losses in the development of central nervous system. The effects on body size (weight, length and head circumference) were more pronounced in newborns of mothers who continued smoking after the first trimester.

It seems important to study the association of growth restriction and other adverse effects with the use of nicotine therapy products, as already demonstrated in animal studies. Until their safety has been proven, caution should be taken when advising pregnant women. Routine collection of information on the use of nicotine replacement products in the Medical Birth Register is needed for more careful follow-up of risk pregnancies and to facilitate 
scientific research on specific effects associated with nicotine replacement products.

\section{Author affiliations}

${ }^{1}$ Department of Environmental and Biological Sciences, University of Eastern

Finland, Faculty of Science and Forestry, Kuopio, Finland

${ }^{2}$ Department of Public Health Solutions, Finnish Institute for Health and Welfare, Kuopio, Finland

${ }^{3}$ School of Pharmacy/Toxicology, University of Eastern Finland, Faculty of Health Sciences, Kuopio, Finland

${ }^{4}$ Department of Information Services, Finnish Institute for Health and Welfare, Helsinki, Finland

${ }^{5}$ Department of Neurobiology, Care Sciences and Society, Karolinska Institute, Stockholm, Huddinge, Sweden

${ }^{6}$ Unit for Obstetrics and Gynecology, Southern Ostrobothnia Central Hospital, Seinäjoki, Finland

Acknowledgements With gratitude, we acknowledge the support for the implementation of MATEX cohort and register-based research infrastructure at the Department of Public Health Solutions and the ROKOSTAT-team, especially Esa Ruokokoski and Jonas Sundman for setting up the Linux Cluster environment and implementing the Medical Birth Register linkage. We also thank the essential support from the Register Holder by Jouni Meriläinen.

Contributors IR, $\mathrm{OH}, \mathrm{KV}$ and MV conceived the research question and designed the study. IR conducted statistical analysis, interpreted the results and wrote the first and subsequent drafts of the manuscript with support of $\mathrm{OH}$. KV, MV, MG and $\mathrm{HdR}$ contributed to data interpretation and revisions of the manuscript. MV, $\mathrm{OH}, \mathrm{KV}$ and IR obtained funding. All authors approved the final version of the submitted manuscript.

Funding This work was supported by the Juho Vainio Foundation (grant numbers 201510322, 201610405, 201710136); NordForsk under the Nordic Programme on Health and Welfare project NordicWelfAir (grant number \#75007); Academy of Finland project BATMAN (grant number 285672), the EU Life project Index Air (grant number LIFE15ENV/PT/000674), Finnish Cultural Foundation North Savo Regional Fund (grant number 65161550) to IKR, and intramural funding by the participating institutes and intramural funding of the institutions.

Disclaimer None of the funding agencies had a role in $n$ the study design; in the collection, analysis and interpretation of the data; in the writing of the report and in the decision to submit the paper for publication.

Competing interests Kirsi Vähäkangas was the chair in 2018-2019 of the scientific advisory committee of the Savuton Suomi (Smoke-free Finland) 2030 initiative.

Patient consent for publication Not required.

Ethics approval The study was approved by the ethics committee of the Northern Ostrobothnia Hospital District (EETTMK 44/2016; issued 18th April 2016). The right to use of register data held by the Finnish Institute for Health and Welfare was granted under the document number THL/838/6.02.00/2016 (issued 22nd June 2016).

Provenance and peer review Not commissioned; externally peer reviewed.

Data availability statement Data may be obtained from a third party and are not publicly available. The Finnish Institute of Health and Welfare is the controller of the Medical Birth Register. Data may be obtained from the register controller (https:// thl.fi/en/web/thlfi-en/statistics/information-on-statistics/register-descriptions/ newborns accessed 29 May 2019).

Open access This is an open access article distributed in accordance with the Creative Commons Attribution Non Commercial (CC BY-NC 4.0) license, which permits others to distribute, remix, adapt, build upon this work non-commercially, and license their derivative works on different terms, provided the original work is properly cited, appropriate credit is given, any changes made indicated, and the use is non-commercial. See: http://creativecommons.org/licenses/by-nc/4.0/.

\section{ORCID iD}

Isabell Rumrich http://orcid.org/0000-0002-7991-2752

\section{REFERENCES}

1 Kramer MS, Séguin L, Lydon J, et al. Socio-Economic disparities in pregnancy outcome: why do the poor fare so poorly? Paediatr Perinat Epidemiol 2000;14:194-210.

2 Wickström R. Effects of nicotine during pregnancy: human and experimental evidence. Curr Neuropharmacol 2007;5:213-22.

3 Banderali G, Martelli A, Landi M, et al. Short and long term health effects of parental tobacco smoking during pregnancy and lactation: a descriptive review. J Trans/ Med 2015;13:327.

4 Reeves S, Bernstein I. Effects of maternal tobacco-smoke exposure on fetal growth and neonatal size. Expert Rev Obstet Gynecol 2008;3:719-30.

5 Sharma D, Farahbakhsh N, Shastri S, et al. Intrauterine growth restriction - part 2. J Matern Fetal Neonatal Med 2016;29:4037-48.

6 Lei X, Zhang Y, Fang F, et al. Choosing the best newborn anthropometric measure associated with the risks and outcomes of intrauterine growth restriction. Clin Pediatr 2015;54:1315-21.

7 Cliver SP, Goldenberg RL, Cutter GR, et al. The relationships among psychosocial profile, maternal size, and smoking in predicting fetal growth retardation. Obstet Gynecol 1992;80:262-7.

8 Blatt K, Moore E, Chen A, et al. Association of reported trimesterspecific smoking cessation with fetal growth restriction. Obstet Gynecol 2015;125:1452-9.

9 Lindley AAet al. Effect of continuing or stopping smoking during pregnancy on infant birth weight, crown-heel length, head circumference, ponderal index, and brain:body weight ratio. Am J Epidemiol 2000;152:219-25.

10 Rumrich IK, Vähäkangas K, Viluksela M, et al. The MATEX cohort - a Finnish population register birth cohort to study health effects of prenatal exposures. BMC Public Health 2017;17:8.

11 Rumrich IK, Vähäkangas K, Viluksela M, et al. Smoking during pregnancy in Finland - Trends in the MATEX cohort. Scand J Public Health 2019;47:890-8.

12 Sankilampi U, Hannila M-L, Saari A, et al. New population-based references for birth weight, length, and head circumference in singletons and twins from 23 to 43 gestation weeks. Ann Med 2013;45:446-54.

13 McLennan JE, Gilles FH, Neff RK. A Model of Growth of the Human Fetal Brain. In: Gilles H, Leviton A, Dooling EC, eds. The developing human brain: growth and epidemiologic neuropathy, 1983: 43-58.

14 Statistics Finland. "Finnish National Classification of Occupations. Available: http://www.stat.fi/meta/luokitukset/ammatti/001-2001/ kuvaus_en.html [Accessed 22 Nov 2017].

15 Zanelli SA, Rogol AD. Short children born small for gestational age outcomes in the era of growth hormone therapy. Growth Horm IGF Res 2018;38:8-13.

16 Gunn CA, Dickson JL, Pretty CG, et al. Brain mass estimation by head circumference and body mass methods in neonatal glycaemic modelling and control. Comput Methods Programs Biomed 2014;115:47-54.

17 Lindley AA, Benson JE, Grimes C, et al. The relationship in neonates between clinically measured head circumference and brain volume estimated from head CT-scans. Early Hum Dev 1999;56:17-29.

18 Salihu HM, Paothong A, Das R, et al. Evidence of altered brain regulatory gene expression in tobacco-exposed fetuses. J Perinat Med 2017;45:1045-53.

19 Chatterton Z, Hartley BJ, Seok M-H, et al. In utero exposure to maternal smoking is associated with DNA methylation alterations and reduced neuronal content in the developing fetal brain. Epigenetics Chromatin 2017;10:4.

20 Ekblad M, Korkeila J, Lehtonen L, et al. Smoking during pregnancy affects foetal brain development. Acta Paediatr 2015;104:12-18.

21 Østgård HF, Løhaugen GCC, Bjuland KJ, et al. Brain morphometry and cognition in young adults born small for gestational age at term. $J$ Pediatr 2014;165:921-7.

22 Räisänen S, Gissler M, Saari J, et al. Contribution of risk factors to extremely, very and moderately preterm births - register-based analysis of 1,390,742 singleton births. PLoS One 2013;8:e60660.

23 Lamminpää R, Vehviläinen-Julkunen K, Gissler M, et al. Smoking among older childbearing women - a marker of risky health behaviour a registry-based study in Finland. BMC Public Health 2013;13:1179.

24 Räisänen S, Gissler M, Sankilampi U, et al. Contribution of socioeconomic status to the risk of small for gestational age infants - a population-based study of 1,390,165 singleton live births in Finland. Int J Equity Health 2013;12:28.

25 Räisänen S, Sankilampi U, Gissler M, et al. Smoking cessation in the first trimester reduces most obstetric risks, but not the risks of major congenital anomalies and admission to neonatal care: a populationbased cohort study of 1,164,953 singleton pregnancies in Finland. $J$ Epidemiol Community Health 2014;68:159-64. 
26 Abraham M, Alramadhan S, Iniguez C, et al. A systematic review of maternal smoking during pregnancy and fetal measurements with meta-analysis. PLoS One 2017;12:e0170946.

27 Chiolero A, Bovet P, Paccaud F. Association between maternal smoking and low birth weight in Switzerland: the EDEN study. Swiss Medical Weekly 2015;135:525-30.

28 Dwyer JB, Broide RS, Leslie FM. Nicotine and brain development. Birth Defects Res C Embryo Today 2008;84:30-44.

29 Slotkin TA. If nicotine is a developmental neurotoxicant in animal studies, Dare we recommend nicotine replacement therapy in pregnant women and adolescents? Neurotoxicol Teratol 2008;30:1-19.

30 Dhalwani NN, Szatkowski L, Coleman T, et al. Nicotine replacement therapy in pregnancy and major congenital anomalies in offspring. Pediatrics 2015;135:859-67.

31 Erickson AC, Arbour LT. Heavy smoking during pregnancy as a marker for other risk factors of adverse birth outcomes: a population- based study in British Columbia, Canada. BMC Public Health 2012;12:102

32 Leonardi-Bee J, Smyth A, Britton J, et al. Environmental tobacco smoke and fetal health: systematic review and meta-analysis. Arch Dis Child Fetal Neonatal Ed 2008;93:F351-61.

33 Gissler M, Meriläinen J, Vuori E, et al. Register based monitoring shows decreasing socioeconomic differences in Finnish perinatal health. J Epidemiol Community Health 2003;57:433-9.

34 Gissler M, Rahkonen O, Arntzen A, et al. Trends in socioeconomic differences in Finnish perinatal health 1991-2006. J Epidemiol Community Health 2009;63:420-5.

35 Vartiainen E, Seppälä T, Lillsunde P, et al. Validation of self reported smoking by serum cotinine measurement in a community-based study. J Epidemiol Community Health 2002;56:167-70. 